\title{
Cronos tudo devora!
}

\section{Cronus devours everything!}

\author{
Ricardo Soares ${ }^{i}$ \\ ' Químico industrial, Instituto Estadual do Ambiente. \\ Rio de Janeiro - RJ - Brasil \\ orcid.org/0000-0002-0353-3174 \\ ricardosoaresuff@gmail.com \\ Paulo Henrique Zuzarte Ferreira ${ }^{i i}$ \\ ii Engenheiro químico, Instituto Estadual do Ambiente. \\ Rio de Janeiro - RJ - Brasil \\ orcid.org/0000-0002-7182-2488 \\ phzuzarte@gmail.com
}

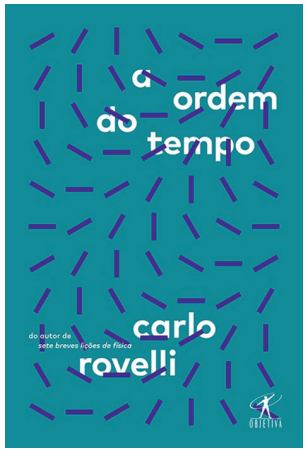

ROVELLI, Carlo. A ordem do tempo. São Paulo: Objetiva. 2018. 192p.

O livro A ordem do tempo foi lançado originalmente em 2017, pelo renomado físico teórico italiano Carlo Rovelli, e traduzido para diversos idiomas. Seus dois livros anteriores, Sete breves lições de física (Rovelli, 2015) e A realidade não é o que parece (Rovelli, 2017), também foram publicados no Brasil, tendo sido o primeiro um bestseller internacional com mais de um milhão de exemplares vendidos, o que configura um fenômeno para um livro de divulgação da física e rendeu ao autor a alcunha de "novo Stephen Hawking".

Assim como em suas obras literárias anteriores, o objetivo de $A$ ordem do tempo é trazer para o grande público uma análise retrospectiva da compreensão humana a respeito dos mistérios que compõem o tempo, desde um passado remoto até o estado da arte atual. A abordagem metodológica é praticamente a mesma dos livros anteriores: resumir conceitos contemporâneos da ciência, evitar detalhamentos e focar no essencial (Rovelli, 2015, 2017). Contudo, dada a natureza complexa e densa do tema escolhido, resta a sensação que dificilmente compreenderão a obra, ao menos em sua totalidade, os leitores não familiarizados com os conteúdos acadêmicos do ciclo básico de física comum a diferentes carreiras universitárias (física, química, engenharia, entre outras), assim como aqueles que não possuam conhecimentos prévios de filosofia, epistemologia ou história da ciência.

O autor é didático e se esforça a todo momento em compor um painel multifacetado a respeito da evolução do entendimento do tempo, utilizando desde os ensinamentos de filósofos pré-socráticos como Anaximandro e Demócrito, passando pelas contribuições de Aristóteles, Newton, Einstein, entre outros. Rovelli $(2018$, p.11) evita uma visão eurocêntrica da evolução do entendimento sobre o assunto, fazendo conexões não usuais, mas enriquecedoras, com ensinamentos budistas e hindus: "A mitologia hindu representa o fluxo cósmico na imagem do deus Shiva que dança: sua dança sustenta o curso do universo, é a passagem do tempo". 
O livro divide-se em três partes, evitando o didatismo e adotando uma linguagem que possibilita a facilidade de leitura por uma ampla gama de leitores, sejam familiarizados ou não com o tema. Contudo, em alguns momentos, o autor peca pelo uso excessivo de floreios.

Na primeira parte, intitulada "A desintegração do tempo", Rovelli tenta mostrar a fragilidade do senso comum diante das desconstruções proporcionadas pelas teorias consolidadas da física. Além disso, elabora uma sofisticada síntese do entendimento do tempo na filosofia de Aristóteles, na física clássica de Newton e na física moderna de Einstein. Todavia, assim como em suas obras anteriores, insiste em contar a história da ciência de forma triunfalista e como consequência do pensamento de raros gênios isolados, e não como fruto de um lento trabalho colaborativo de múltiplas gerações.

Na segunda parte, "O mundo sem tempo", Rovelli (2018, p.81) apresenta o argumento de que o mundo é mutável e constituído basicamente por uma rede de sucessivos acontecimentos, isto é, "o mundo não é um conjunto de coisas, é um conjunto de eventos". Então, seria tarefa da física descrever as relações entre os múltiplos eventos, com o agravante de que "os eventos do mundo não se organizam em fila como os ingleses. Eles se amontoam em caos como os italianos" (p.80).

Por mais que tenha se esforçado em ser inteligível, Rovelli, ao descrever a sua moderna teoria da gravidade quântica em loop, não consegue ser claro o suficiente para um público não acostumado com a física. Além disso, vê-se na obrigação de indicar leituras complementares especializadas para um maior detalhamento do assunto, dentre elas seu livro prévio A realidade não é o que parece (Rovelli, 2017).

Na terceira e última parte, "As fontes do tempo", o autor, utilizando alguns aspectos da mecânica quântica e da termodinâmica, tenta elucidar como foram construídas as ilusões a respeito do tempo, devido principalmente à incapacidade humana de perceber o mundo em todos os seus detalhes infinitesimais. Nessa parte, o autor tenta "reconstruir o tempo", apresentando a sua "hipótese do tempo térmico", desenvolvida em conjunto com o matemático francês Alain Connes. Essa parte é sem dúvida a de mais difícil compreensão para um público não familiarizado com conceitos inerentes à física. Ciente disso, o autor sugere que o leitor pule os capítulos 9 e 10, caso os ache difíceis demais. Além disso, Rovelli se viu obrigado a elaborar um resumo explicativo desses capítulos para aqueles leitores que tenham tentado lê-los e não os tenham compreendido.

O livro A ordem do tempo traz interessantes considerações e valiosas contribuições ao divulgar importantes e inquietantes questões da física moderna, mas não cumpre sua principal proposta de revelar os enigmas do tempo para o público leigo. Contudo, para o leitor iniciado nos conhecimentos da física, da filosofia e história da ciência, é uma obra essencial para o entendimento de um amplo panorama histórico a respeito do que é conhecido como tempo.

\section{REFERÊNCIAS}

ROVELLI, Carlo.

A ordem do tempo. Rio de Janeiro: Objetiva. 2018.

ROVELLI, Carlo.

A realidade não é o que parece. Rio de Janeiro:

Objetiva. 2017.
ROVELLI, Carlo.

Sete breves lições de física. Rio de Janeiro:

Objetiva. 2015. 